\begin{tabular}{c|c|c}
\hline \hline Vol. 249: 305-310, 2003 & MARINE ECOLOGY PROGRESS SERIES \\
Mar Ecol Prog Ser & Published March 10 \\
\hline
\end{tabular}

NOTE

\title{
Penguins predict their performance
}

\author{
Rory P. Wilson* \\ Institut für Meereskunde, Düsternbrooker Weg 20, 24105 Kiel, Germany
}

\begin{abstract}
New technology has allowed inter-dive oxygenloading behaviour to be assessed in free-living Magellanic penguins Spheniscus magellanicus and shows, via pre-dive hyperventilation and oxygen loading, that birds predict both their upcoming dive performance in terms of duration and depth, and foraging success based on the number of prey they are likely to catch. Thus wild penguins make decisions based on complex environmental parameters and this leads to particularly efficient time use as expected according to optimized foraging.
\end{abstract}

KEY WORDS: Oxygen loading · Optimal foraging $\cdot$ Predator prey interactions $\cdot$ Magellanic penguin

Resale or republication not permitted without written consent of the publisher

Optimal foraging theory (MacArthur \& Pianka 1966, Schoener 1986, Stephens \& Krebs 1986) purports that animals in complex environments should hunt so as to maximize net energy gain (Perry \& Pianka 1997). Inherent, though often not explicit, in this is that animals must physiologically prepare (Wehner 1997) for their elected action (Axelrod \& Reisine 1984). Thus, where possible, careful assessment of physiological preparation for particular actions may help researchers elucidate the type of decision being made and its likely outcome (Wehner 1997). Diving endotherms lend themselves to such studies since these animals go through profound physiological changes during foraging and many foraging decisions are presumed to be made at the surface when oxygen is being loaded for the subsequent dive (Thompson \& Fedak 2001). All airbreathing marine animals feed underwater and, during foraging, can increase their chances of successfully encountering prey per unit time by minimizing the time spent at the surface where gas exchange takes place (Le Boeuf et al. 2000). The degree to which the body must be loaded with oxygen is a primary factor determining the time at the surface between dives (Butler \& Jones 1997, Webb et al. 1998). However, since the rate of oxygen uptake is inversely propor- tional to body oxygen levels, animals with low body oxygen saturation accumulate oxygen most rapidly (Butler \& Jones 1997). In order to minimize time at the surface, air-breathing animals should dive with just enough oxygen to last them for the following dive (Kramer 1988). This should lead to strong selection pressure for diving animals to prepare appropriately for subsequent dives, a condition which requires information on the likely performance, a proxy for oxygen use (Culik et al. 1994), during the course of the dive. The condition is particularly pertinent for animals feeding on patchy, mobile prey where prolonged periods underwater are expected when animals feed extensively from a patch, interspaced with multiple dives where no prey are encountered. Overloading with oxygen for searching dives wastes time at the surface, but submergences executed with just enough oxygen to complete the search dive are highly disadvantageous if prey are encountered since the patch cannot then be exploited.

To examine whether free-living animals might resolve this problem, Magellanic penguins foraging off southern Argentina were fitted with depth- and beakangle loggers which provided information on the time spent at the sea surface between dives, the no. of breaths taken at this time and the no. of fish caught during dives.

Materials and methods. Three Magellanic penguins brooding small chicks during November and December 2000 at the Cabo Virgenes colony $\left(52^{\circ} 24^{\prime} \mathrm{S}\right.$, $68^{\circ} 26^{\prime} \mathrm{W}$ ) in Santa Cruz, Argentina, were fitted with intermandibular angle sensors (IMASEN, Driesen \& Kern) and time-depth gauges (TDR, Lotek). The former consisted of a Hall sensor $(2 \times 3 \mathrm{~mm}$ diam.) linked, via a thin cable, to a logger (Wilson et al. 2002a). The sensor, which was fixed to the upper beak using a drop of 2-component epoxy, sensed magnetic-field strength from a small neodinium boron magnet $(2 \times 2 \times 1 \mathrm{~mm})$ attached similarly to the lower beak. Magnetic-field strength registered by the sensor varied with beak 
angle. The relationship between Hall sensor output and beak angle was ascertained by allowing the birds to bite rods of known diameters while noting the position within the beak at which the rod was bitten as well as the beak and head measurements. Simple trigonometry allowed calculation of the beak angle. The loggers were fixed with tape (Wilson et al. 1997) to the feathers of the bird's lower back to minimize drag (Bannasch et al. 1994) and started using a laptop computer and interface. Data were recorded at $10 \mathrm{~Hz}$ in the logger $(133 \times 25 \times 19 \mathrm{~mm}$, mass $56 \mathrm{~g})$. The cable between the sensor and the logger was placed over the back of the bird's head and directly down the bird's back to the logger, being held in place by spots of glue at intervals. Birds were also fitted at the leg with TDRs $(57 \times 18 \mathrm{~mm}$ diam., mass $16 \mathrm{~g})$ set to record pressure at $1 \mathrm{~Hz}$. Units were left in place for 1 foraging trip before being removed.

Data from the loggers were analysed using MT-FLIP (Jensen Software Systems) where beak angle data were transformed from Hall sensor output $(\mathrm{mV})$ to beak opening angles and displayed graphically adjacent to the depth data. Prey capture was apparent in clear periods where the beak was opened while the birds were at depth (Wilson et al. 2002a), while breaths taken at the surface were apparent as a series of regular, symmetrical peaks between dives (Wilson et al. 2002a).

Typical prey for the region are Odontesthes smitti, Sprattus fuegensis and squid species, which account for $>80 \%$ of all prey items taken at this site (Scolaro et al. 1999). Ingestion of prey by the penguins at Cabo Virgenes results in beak-opening angles of up to ca. $12^{\circ}$ for generally $<2 \mathrm{~s}$. Typically, the ingestion of prey items resulted in a single peak in beak angle over time with a skew to the right-hand side due to the elongated rear section of the fish passing the rictus (see Fig. 1; cf. Wilson et al. 2002a). Based on work with captive penguins (Wilson et al. 2002a), ingestion of 1 prey item was considered to have taken place when the beak angle exceeded $2^{\circ}$ at depth, the event ending when the beak angle returned to base level.

Work with 10 conspecific Humboldt penguins Spheniscus humboldti in a physiology laboratory in La Serena, Chile, showed that during periods of exertion birds opened and closed their beaks once per breath cycle and that tidal volume was related to maximum beak angle (Wilson et al. in press). However, the gradient and intercept of the regression of maximum beak angle against the tidal volume showed high variability between individuals (Wilson et al. in press).

Assessment of the breath data showed an invariant pattern of beak angles during periods at the surface within a dive bout: high beak angles with the first breaths decreased to minima and then increased to maxima again before the bird dived (Wilson et al. in press; Fig. 1). The surface pauses following the last dives in bouts were also always followed by the initial peaks in beak angle, decreasing to the minima. These minima did not increase, however, until the birds were ready to dive again in the proximate bout, whereupon they increased in a manner similar to that observed in the pauses within dive bouts (Wilson et al. in press; Fig. 1). The initial sequential decreases in beak angle during breathing at the surface were thus ascribed to dive recovery and the subsequent sequential increases ascribed to dive preparation. Breaths taken for each of these processes were counted. The exact time at which the birds switched from recovery to preparation was determined to be either the peak of a single breath, if this breath had the smallest peak and adjacent peaks to the left and right differed by $>0.5^{\circ}$, or the interpeak interval between 2 adjacent breaths if these 2 breaths had the smallest peaks and both differed from each other by $<0.5^{\circ}$. In the former case, recovery was taken to be the no. of those breaths to the left of the minimum plus a half breath (corresponding to half of the minimum), while preparation was the no. of breaths to the right of the minimum peak plus a half breath. In the latter case, 1 of the 2 minima was ascribed to recovery and the other to preparation.

Results. The 3 Magellanic penguins studied foraged at sea for periods of 9.6 to $21.6 \mathrm{~h}$ and dived between 365 and 1705 times (Table 1). All birds returned to the nest in good condition having fed appreciably, as was apparent from their protruding bellies, from the fact that they fed their chicks and from inspection of the IMASEN traces.

For all 3 birds there was a clear relationship between maximum depth reached during the dive and dive duration (Fig. 2a, Table 1) and between the rate of descent and maximum depth reached during the dive (Fig. 2b, Table 1). In addition, both dive duration (Fig. 3a) and maximum depth reached during the dive (Fig. 3b) were correlated with the number of pre-dive breaths (Table 1). Much of the variance in the data shown in Fig. 3 could be explained in terms of the amount of prey captured per dive: more pre-dive breaths were consecrated for dives to a particular depth if prey were captured during the previous dive (Fig. 4a, Table 1) although no such relationship was apparent for periods longer than 1 dive cycle. Finally, although there was considerable variance, there was a clear, positive relationship between the number of prey caught in any dive $\mathrm{N}$ and the number of prey caught in dive $\mathrm{N}+1$ (Fig. $4 \mathrm{~b}$, Table 1).

Discussion. This study makes it clear that Magellanic penguins prepare extensively for dives before they are executed, rather than simply modifying dives as they are executed in accordance with the condi- 


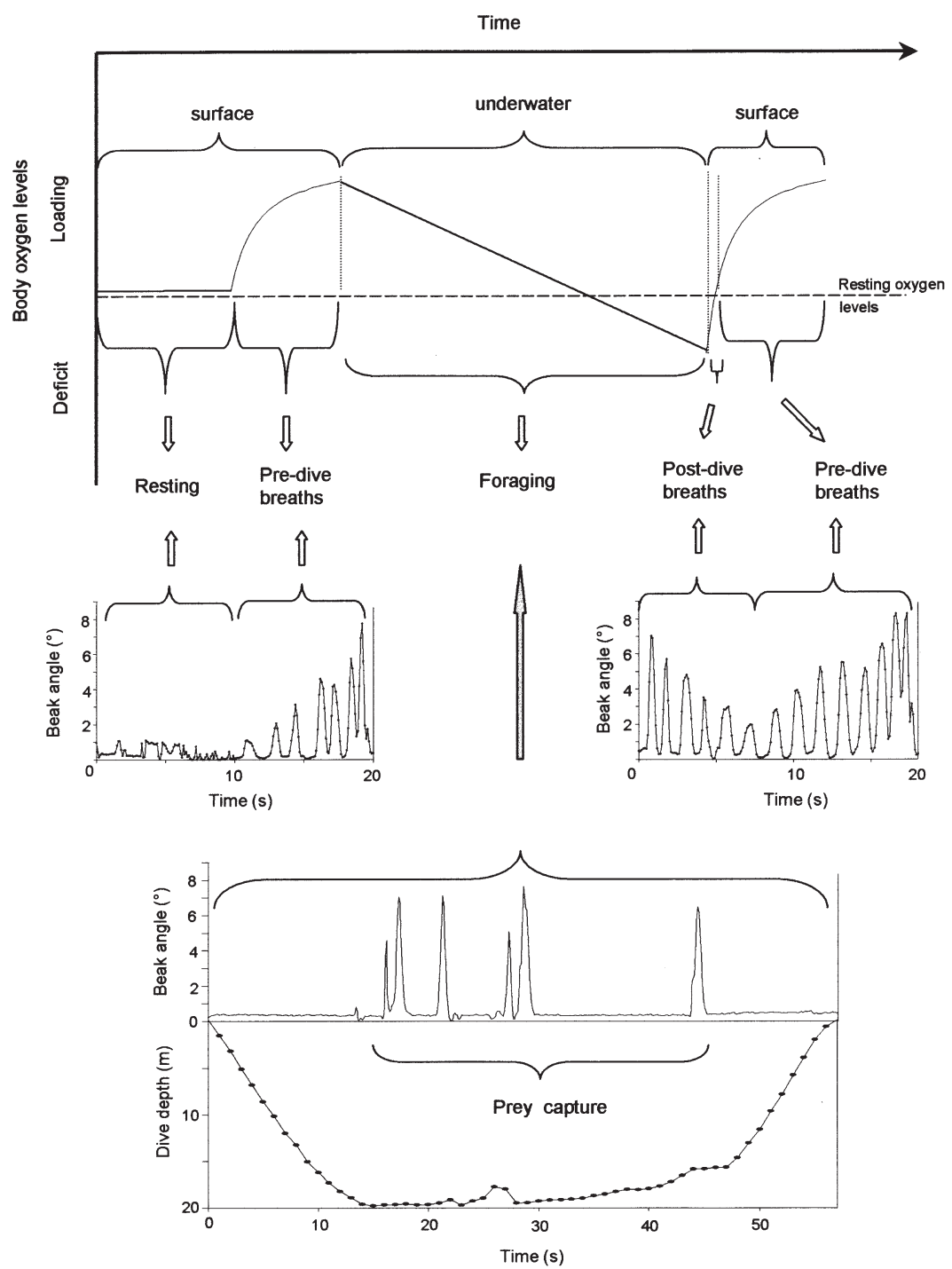

Fig. 1. Spheniscus magellanicus. Body oxygen levels in a foraging penguin superimposed with data on beak angle and dive depth. Graphs in the centre of the figure show beak opening due to breaths while the bird is at the surface. Lower graph shows the capture of 6 prey during the dive

tions, both physiological and environmental, that occur during the course of the dive. This is apparent from the rate of descent and maximum depth data where, from the moment the birds begin the descent phase of the dive, vertical velocities are higher in birds that dive deeper (Fig. 2) (cf. Wilson \& Peters 1999). However, even before this, when birds are at the surface, breaths are taken according to projected dive duration and depth (Fig. 3). Thus, the premise that marine endotherms use the time at the surface solely to recover from the previous dive (e.g. Le Boeuf et al. 2000) appears incorrect. Although the time at the surface does have a recovery component (Fig. 1), it is also apparently concerned to a large extent with appropriate preparation for the following dive and, as such, must be coupled with information about the projected dive performance. Dive performance will incorporate a duration component but it is also relevant that birds apparently assess the likelihood of prey capture by preparing for dives according to the amount of prey they had caught in the previous dive (Fig. 4a). The utility of doing this becomes clear if the no. of prey caught in adjacent dives is examined because, despite considerable variance, the no. of prey caught in any dive $\mathrm{N}$ can be used to predict the no. of prey likely to be caught in dive $\mathrm{N}+1$ (Fig. 4b). It should be noted here that a central premise behind selection pressures leading to change is that even if there is only a marginal benefit to be derived by adopting a particular strategy, in the long run, individuals that adopt the strategy will do better than conspecifics that do not. Thus, even large variance does not preclude the observed patterns from exerting selection pressure. Correlations between foraging success in adjacent dives probably stem from the patchiness of the prey distribution but the high variance makes it unwise to use fits from the regressions to make any statement about the form this distribution might take until a much higher sample size is obtained.

There are relatively few examples of studies of optimized foraging in freeliving animals (Goss-Custard 1977, Pyke et al. 1977), most seminal work being conducted on captive animals where observations are facilitated under controlled conditions (Perry \& Pianka 1997). The case for apparent optimized foraging in free-living penguins could be strengthened if theoretical calculations of foraging success were modelled using different pre-dive breath numbers. However, the free-living situation is highly complex, making such models tenuous; beak angle is not constant over the pause cycle (Wilson et al. 2002a) so tidal volume varies (see 'Materials and methods') from breath to breath (Fig. 1), probably affecting gas exchange rate (Davis \& Kanatous 1999, Wilson et al. in press). In addition, changes in buoyancy with depth (Skrovan et al. 1999, Sato et al. 2002) will affect energy expenditure, as will changes in speed associated with prey capture (Wilson et al. 2002b), and gas exchange of both oxygen and carbon dioxide must be considered (Butler \& Jones 1997, Webb et al. 1998). Nevertheless, the solution 

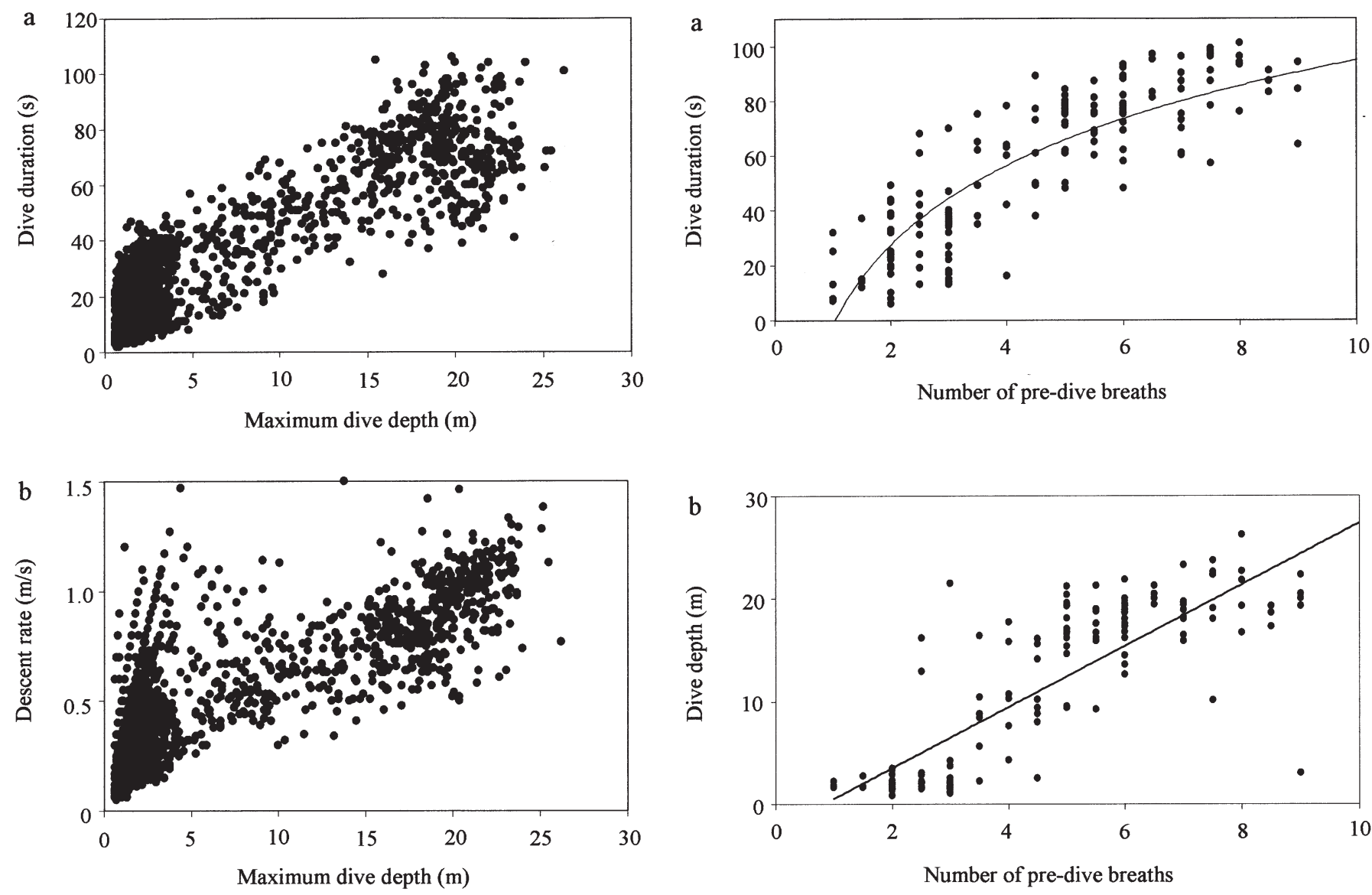

Fig. 2. Spheniscus magellanicus. Relationship between maximum depth reached during a dive and (a) dive duration and (b) rate of descent for a Magellanic penguin $(\gamma)$ fitted with a beak-angle logger and depth gauge and foraging off Cabo Virgenes, Argentina

Fig. 3. Spheniscus magellanicus. Numbers of pre-dive breaths in relation to (a) dive duration and (b) maximum dive depth for a Magellanic penguin $(\gamma)$ fitted with a beak-angle logger and depth gauge and foraging off Cabo Virgenes, Argentina

Table 1. Spheniscus magellonieus. Foraging parameters of 3 penguins $(\alpha, \beta, \gamma)$ with fixed beak angle sensors. In regression descriptions, the first listed parameter is $y$, the second $x$

\begin{tabular}{|c|c|c|c|}
\hline Parameters & $\alpha$ & $\beta$ & $\gamma$ \\
\hline Length of foraging trip (h) & 21.6 & 9.6 & 21.3 \\
\hline No. of dives conducted & 1153 & 365 & 1705 \\
\hline $\begin{array}{l}\text { Dive duration (s) vs } \\
\text { max dive depth (m) }\end{array}$ & $\begin{array}{l}y=2.43 x+33 \\
\left(r^{2}=0.69, p<0.001\right)\end{array}$ & $\begin{array}{l}y=1.76 x+33 \\
\left(r^{2}=0.69, p<0.001\right)\end{array}$ & $\begin{array}{l}y=3.0 x-2.4 \\
\left(r^{2}=0.67, p<0.001\right)\end{array}$ \\
\hline $\begin{array}{l}\text { Descent rate }\left(\mathrm{m} \mathrm{s}^{-1}\right) \text { vs } \\
\text { max dive depth }(\mathrm{m})\end{array}$ & $\begin{array}{l}y=0.03 x+0.23 \\
\left(r^{2}=0.66, p<0.001\right)\end{array}$ & $\begin{array}{l}y=0.05 x+0.15 \\
\left(r^{2}=0.73, p<0.001\right)\end{array}$ & $\begin{array}{l}y=0.03 x+0.31 \\
\left(r^{2}=0.58, p<0.001\right)\end{array}$ \\
\hline $\begin{array}{l}\text { Dive duration (s) vs } \\
\text { no. pre-dive breaths }\end{array}$ & $\begin{array}{l}y=29.4 \ln x+18.4 \\
\left(r^{2}=0.70, p<0.001\right)\end{array}$ & $\begin{array}{l}y=23.3 \ln x+24.3 \\
\left(r^{2}=0.62, p<0.001\right)\end{array}$ & $\begin{array}{l}y=41.7 \ln x-1.3 \\
\left(\mathrm{r}^{2}=0.70, \mathrm{p}<0.001\right)\end{array}$ \\
\hline $\begin{array}{l}\text { No. pre-dive breaths for } \\
\text { dive } \mathrm{N}+1 \text { vs no. prey } \\
\text { caught in dive } \mathrm{N}\end{array}$ & $\begin{array}{l}y=0.28 x+4.2 \\
\left(r^{2}=0.31, p<0.05\right) \\
(\text { depth } 16-19 \mathrm{~m})\end{array}$ & $\begin{array}{l}y=0.21 x+5.1 \\
\left(\mathrm{r}^{2}=0.22, \mathrm{p}<0.05\right) \\
(\text { depth } 19-22 \mathrm{~m})\end{array}$ & $\begin{array}{l}y=0.29 x+6.0 \\
\left(r^{2}=0.26, p<0.05\right) \\
(\text { depth } 18-20 \mathrm{~m})\end{array}$ \\
\hline $\begin{array}{l}\text { No. of prey items caught } \\
\text { in dive } \mathrm{N}+1 \text { vs no. of } \\
\text { prey caught in dive } \mathrm{N}\end{array}$ & $\begin{array}{l}y=0.48 x+0.6 \\
\left(r^{2}=0.23, p<0.001\right)\end{array}$ & $\begin{array}{l}y=0.44 x+2.6 \\
\left(r^{2}=0.19, p<0.001\right)\end{array}$ & $\begin{array}{l}y=0.21 x+1.0 \\
\left(r^{2}=0.002, p<0.05\right)\end{array}$ \\
\hline
\end{tabular}



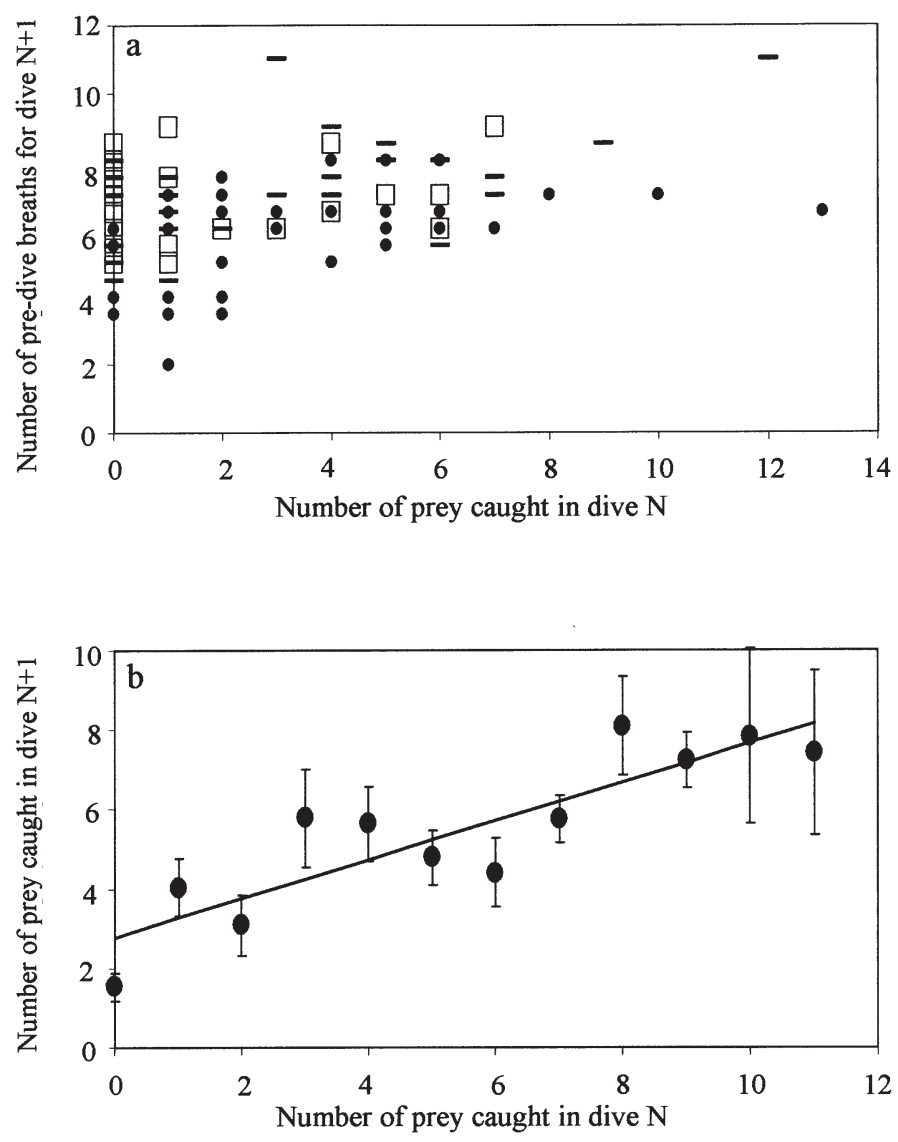

Fig. 4. Spheniscus magellanicus. (a) No. of prey items caught in dive $\mathrm{N}$ in relation to no. of pre-dive breaths taken for dive $\mathrm{N}+1$ showing data from all 3 birds $(\alpha, \beta, \gamma)$ for specific depth ranges (to reduce the variance added by depth). Depth ranges are 16 to $19 \mathrm{~m}(\bullet$ from $\beta), 18$ to $20 \mathrm{~m}$ ( $\square$ from $\gamma$ ) and 19 to $22 \mathrm{~m}$ ( - from $\alpha$ ). (b) No. of prey items caught in dive $\mathrm{N}$ in relation to no. of prey caught in dive $\mathrm{N}+1$. The data are taken from a single bird $(\beta)$ over the whole foraging trip and all depth ranges. indicates mean and the vertical bar standard error

exhibited by penguins is intuitively correct and demonstrates that, where particular strategies always lead to predictable physiological conditions, such as is apparent with searching dives at different depths, correct physiological preparation is beneficial even if the mechanisms linking the decision to the preparation are not clear (Wehner 1997). Such a strategy demonstrates that penguins make decisions based on complex environmental parameters (Krebs \& Kacelnik 1991) and this leads to particularly efficient time use (Schoener 1986, Cuthill \& Houston 1997) as expected according to optimized foraging. Preparation may take the form of tachy/bradycardia (Bevan et al. 1997, Hawkins et al. 2000), a recognised purely physiological process, or of an increased no. of pre-dive breaths, which is at least a partially behavioural phenomenon.
However, increased nos. of pre-dive breaths associated with perceived increases in prey concentrations must be considered to be a primarily behavioural response. A response of this type is based on an assessment of net energy gain per unit time and is thus fundamental to much of optimal foraging and effective exploitation of patchily distributed prey (Stephens \& Krebs 1986). Future work, based on consideration of both animal physiology and behaviour, should help clarify inconsistencies in optimal foraging theory (Gray 1987) by helping us to understand the decisions made by animals foraging in complex environments. Ultimately, perhaps, such work might demonstrate that even intractable species, such as highly mobile freeliving marine predators, might adhere to optimized foraging in the same way as many species more conveniently examined in captivity (Krebs \& Kalcenik 1991, Perry \& Pianka 1997).

Acknowledgements. Thanks are extended to Alejandro Simeone, Antje Steinfurth, Guillermo Luna, Niko Liebsch and Silvina Sturtzenbaum for extensive help during this work. The field work was approved by the Consejo Agrario of Santa Cruz Province and the laboratory work by CONAF, Chile. Funding was received from ICSU.

\section{LITERATURE CITED}

Axelrod J, Reisine TD (1984) Stress hormones: their interaction and regulation. Science 224:452-459

Bannasch R, Wilson RP, Culik B (1994) Hydrodynamic aspects of design and attachment of a back-mounted device in penguins. J Exp Biol 194:83-96

Bevan RM, Boyd IL, Butler PJ, Reid K, Woakes AJ, Croxall JP (1997) Heart rates and abdominal temperatures of freeranging South Georgian shags Phalacrocorax georgianus. J Exp Biol 200:661-675

Butler PJ, Jones DR (1997) Physiology of diving of birds and mammals. Physiol Rev 77:837-899

Culik BM, Wilson RP, Bannasch R (1994) Under-water swimming at low energetic cost by pygoscelid penguins. J Exp Biol 197:65-78

Cuthill IC, Houston AI (1997) Sensor systems and behaviour. In: Krebs JR, Davis NB (eds) Managing time and energy: an evolutionary approach. Blackwell Science, Oxford, p 97-120

Davis RW, Kanatous SB (1999) Convective oxygen transport and tissue oxygen consumption in weddell seals during aerobic divies. J Exp Biol 202:1091-1113

Goss-Custard JD (1977) Optimal foraging and the size selection of worms by redshank Tringa totanus. Anim Behav 25:10-29

Gray RD (1987) Faith and foraging: a critique of the 'paradigm argument from design'. In: Kamil AC, Krebs JR, Pulliam HR (eds) Foraging behavior. Plenum Press, New York, p 69-140

Hawkins PAJ, Butler PJ, Woakes AJ, Speakman JR (2000) Estimation of the rate of oxygen consumption of the common eider duck (Somateria mollissima), with some measurements of heart rate during voluntary dives. J Exp Biol 203:2819-2832 
Kramer DL (1988) The behavioral ecology of air breathing by aquatic animals. Can J Zool 66:89-94

Krebs JR, Kacelnik A (1991) Decision making. In: Krebs JR, Davis NB (eds) Behavioural ecology: an evolutionary approach. Blackwell Science, Oxford, p 105-136

Le Boeuf BJ, Crocker DE, Grayson J, Gedamke J, Webb PM, Blackwell SB, Costa DP (2000) Respiration and heart rate at the surface between dives in northern elephant seals. J Exp Biol 203:3265-3274

MacArthur RH, Pianka ER (1966) On the optimal use of a patchy environment. Am Nat 102:603-609

Perry G, Pianka ER (1997) Animal foraging: past, present and future. Trends Ecol Evol 12:360-364

Pyke GH, Pulliam HR, Charnov EL (1977) Optimal foraging: a selective review of theory and tests. Q Rev Biol 52:137-154

Sato K, Naito Y, Kato A, Niizuma Y and 5 others (2002) Buoyancy and maximal diving depth in penguins: do they control inhaling air volume. J Exp Biol 205:1189-1197

Schoener TW (1986) A brief history of optimal foraging theory. In: Kamil AC, Krebs JR, Pulliam HR (eds) Foraging behavior. Plenum Press, New York, p 5-68

Scolaro JA, Wilson RP, Laurenti S, Kierspel M, Gallelli H, Upton JA (1999) Feeding preferences of the Magellanic penguin over its breeding range in Argentina. Waterbirds 22:104-110

Skrovan RC, Williams TM, Berry PS, Moore PW, Davis RW (1999) The diving physiology of bottlenose dolphins (Tursiops truncatus). II. Biomechanics and changes in buoyancy at depth. J Exp Biol 202:2749-2761

Editorial responsibility: Otto Kinne (Editor), Oldendorf/Luhe, Germany
Stephens DW, Krebs JR (1986) Foraging theory. Princeton University Press, Princeton, NJ

Thompson D, Fedak MA (2001) How long should a dive last? A simple model of foraging decisions by breath holders in a patchy environment. Anim Behav 61:287-296

Webb PM, Andrews RD, Costa DP, Le Boeuf BJ (1998) Heart rate and oxygen consumption of northern elephant seals during diving in the laboratory. Physiol Zool 71:116-125

Wehner R (1997) Sensor Systems and Behaviour. In: Krebs JR, Davis NB (eds) Behavioural ecology: an evolutionary approach. Blackwell Science, Oxford, p 19-41

Wilson RP, Peters G (1999) The foraging behaviour of Chinstrap penguins Pygoscelis antarctica at Ardley Island, Antarctica. Mar Ornithol 27:69-79

Wilson RP, Pütz K, Peters G, Culik B, Scolaro JA, Charrassin JB, Ropert-Coudert Y (1997) Long term attachment of transmitting and recording devices to penguins and other seabirds. Wildl Soc Bull 25:101-106

Wilson RP, Steinfurth A, Ropert-Coudert Y, Kato A, Kurita M (2002a) Lip-reading in remote subjects: an attempt to quantify and separate ingestion, breathing and vocalisation in free-living animals. Mar Biol 140:17-27

Wilson RP, Ropert-Coudert Y, Kato A (2002b) Rush and grab strategies in foraging marine endotherms: the case for haste in penguins. Anim Behav 63:85-95

Wilson RP, Simeone A, Luna-Jorquera G, Steinfurth A, Jackson S, Fahlman A (2003) Patterns of respiration in diving penguins: is the last gasp an inspired tactic? J Exp Biol (in press)

Submitted: June 11, 2002; Accepted: January 8, 2003 Proofs received from author(s): February 14, 2003 